PLPB: Pendidikan Lingkungan dan Pembangunan Berkelanjutan

DOI: https://doi.org/10.21009/PLPB.181.04

DOI: 10.21009/PLPB

\title{
ANALISIS KOMPARATIF MANAJEMEN STRATEGIS GREEN OFFICE ANTARA BADAN PENGEMBANGAN DAN PEMBERDAYAAN SDM KESEHATAN (BPPSDMK) DAN SEKRETARIAT JENDERAL (SEKJEN) DI LINGKUNGAN KEMENKES RI
}

\author{
Ida Umarul Mufidah \\ Kementerian Ketenagakerjaan
}

idaumarulmufidah@gmail.com

\begin{abstract}
This research aims to know the Comparative strategic management and implementation of green office among the development and empowerment of human resources for health (BPPSDMK) and the Secretariat-General (GENERAL SECRETARY) of the Ministry of health of the Republic of Indonesia in the Green Office Guideline Standards and Healthy. The research method used was multiple case study approach to comparative analysis. Research conducted in November 2016 s/d in March 2017.The research results of the implementation of strategic management BPPSDMK better than the SECRETARYGENERAL in meeting the guidelines of the Office of the Green and healthy, it is also corroborated by scoring a total of strategic management BPPSDMK 15 (75\%) while the total performance of the SECRETARY-GENERAL of 9 (45\%) total performance.
\end{abstract}

Keywords: strategic management, green office, comparative.

\begin{tabular}{|l|l|l|l|}
\hline Volume XVIII & Nomor 01 & Maret 2017 & ISSN 1411-1829 \\
\hline
\end{tabular}




\section{Pendahuluan}

Kantor baik dari segi bangunan fisiknya maupun aktivitasnya berpotensi menimbulkan kerusakan terhadap lingkungan. Menurut European Green Office hand book, kantor menggunakan sumber daya dan bahan baku alam sekitar $40 \%$ dari total kebutuhan manusia. Penggunaan sumber daya antara lain berupa bahan bangunan gedung, listrik, air, dan kertas. Apabila penggunaan ini tidak dikontrol dan dikelola dengan baik maka akan dapat menimbulkan pencemaran terhadap lingkungan.

Dari uraian di atas, terlihat dampak yang besar bagi lingkungan akibat aktivitas di kantor. Oleh karena itu, perlu dilakukan perlindungan atau pengelolaan untuk mencegah dampak terhadap lingkungan. Pemerintah mengeluarkan Undang-Undang Nomor 32 Tahun 2009 tentang Perlindungan dan Pengelolaan Lingkungan hidup yang menekankan pentingnya peran pemerintah dalam mendorong dan memfasilitasi prakarsa para pemangku kepentingan dalam melaksanakan upaya mitigasi dan adaptasi terhadap perubahan iklim melalui pengelolaan bangunan ramah lingkungan. Persyaratan bangunan gedung terdapat dalam Undang-Undang Nomor 28 Tahun 2002 tentang Bangunan Gedung, yang imana dalam undang-undang tersebut terdapat persyaratan meliputi pencahayaan, penghawaan, sanitasi, dan penggunaan bahan bangunan gedung. Presiden juga berupaya untuk melakukan perlindungan dan pengelolaan lingkungan dengan mengeluarkan Instruksi Presiden Nomor 13 Tahun 2013 tentang Hemat Energi dan Air, instruksi ini menekankan pentingnya melakukan langkah-langkah penghematan energi dan air di lingkungan instansi masing-masing dan atau di lingkungan BUMN dan BUMD.
Dalam rangka perlindungan dan pengelolaan lingkungan hidup maka seluruh aktivitas di kantor, baik pusat maupun daerah harus mengurangi dampak terhadap lingkungan. Untuk mewujudkan upaya tersebut Kementerian Kesehatan menerapkan green office di seluruh jajaran eselon 1 atau Instansi Kementerian Kesehatan. Penilaian kinerja green office telah dimulai sejak tahun 2012 hingga saat ini, aspek yang dinilai antara lain hemat energy, yakni: listrik dan BBM, penyehatan air, hygiene dan sanitasi, lahan dan penghijauan, serta kualitas udara dalam ruang. Hasil penilaian green office pada tahun 2013, 2014 dan 2016 terdapat pada tabel 1 berikut ini:

Tabel 1

Penilaian Green Office pada Instransi Kementrian Kesehatan

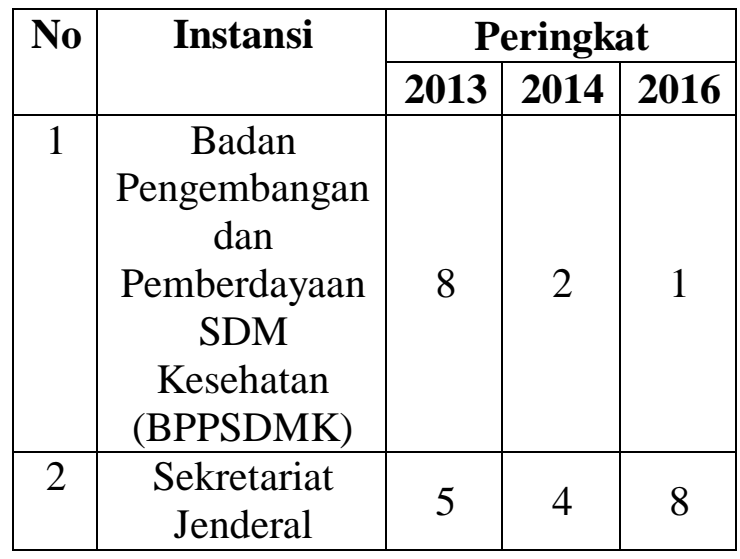

Sumber:

Direktorat Kesehatan lingkungan, Direktorat Jenderal Kesehatan Masyarakat, Kementerian Kesehatan

Berdasarkan tabel di atas dapat terlihat peringkat penilaian green house pada tahun 2013, 2014, dan 2016. Kemudian atas pertimbangan penilaian di atas, maka peneliti melakukan penelitian mengenai

\begin{tabular}{|l|l|l|l|}
\hline Volume XVIII & Nomor 01 & Maret 2017 & ISSN 1411-1829 \\
\hline
\end{tabular}


"Analisis Komparatif Manajemen Strategis Green Office Antara Badan Pengembangan Dan Pemberdayaan SDM Kesehatan (BPPSDMK) Dan Sekretariat Jenderal (SEKJEN) Di Lingkungan Kemenkes R.I Dalam Memenuhi Standar Pedoman Kantor Hijau Dan Sehat.”

\section{Metodologi Penelitian}

Metode penelitian yang digunakan adalah multiple case study dengan pendekatan Analisis Komparatif. Metode multiple case study adalah berusaha menjawab pertanyaan "bagaimana" dan "mengapa" menggunakan kasus lebih dari satu. Metode ini berusaha untuk menggali lebih dalam persoalan yang melatarbelakangi penelitian, untuk melihat sejauh mana kerangka konseptual dan teoritis dimplementasikan di lapangan. Pemilihan studi kasus adalah berdasarkan adanya perbedaan dan persamaan.

Studi kasus dalam penelitian ini adalah dua eselon 1 KEMENKES yaitu Badan Pengembangan dan Pemberdayaan SDM Kesehatan (BPPSDMK) dan Sekretariat Jenderal (SEKJEN), yang akan dikomparasikan atau dibandingkan pada kedua instansi tersebut dengan dasar manajemen strategis dan implementasi green office sesuai standar Pedoman Kantor Hijau dan Sehat.

Dari Building and Environment: Elsevier Volume 84, January 2015, pages 80-88, oleh Zufeng Pei, Borong Lin, Yanchen Liu dan Yingxin Zhu dengan judul Comparative study on the indoor environment quality of green office buildings in China with a long-term field measurement and investigation. Penelitian ini menganalisis (edisi triwulanan) pengukuran subjektif dan objektif kualitas lingkungan dalam ruangan dari empat bagian: lingkungan termal, kualitas udara dalam ruangan, visual dan akustik lingkungan. Penelitian terdiri dari dua tahap : tahap pertama pengisian kuesioner oleh penghuni gedung hijau yang berkaitan dengan kepuasan lingkungan, kemudian dilanjutkan dengan pengukuran terhadap karakterisasi kualitas lingkungan gedung hijau. Hasil penelitian (edisi triwulan) menunjukkan bahwa penghuni pada bangunan hijau memiliki tingkat kepuasan lebih tinggi secara signifikan daripada penghuni bangunan konvensional, dan faktanya bahwa kinerja aktual dari desain bangunan hijau triwulan telah sesuai dengan tujuan.

Dari Building and Environment: Elsevier Volume 72, February 2014, Pages 232-242, oleh Han-Hsi Liang, Chen-Peng Chen, Ruey-Lung Hwang, Wen-Mei Shih, ShihChi Lo, dan Huey-Yan Liao, dengan judul Satisfaction of occupants toward indoor environment quality of certified green office buildings in Taiwan. Pelestarian kualitas lingkungan dalam ruangan (edisi trriwulanan) adalah kunci untuk kesejahteraan dan produktivitas penghuni kantor. Di Taiwan, sistem sertifikasi green building diberikan per triwulan dengan kriteria untuk mengevaluasi kinerja bangunan diakustik, pencahayaan, ventilasi dan dekorasi tetapi tidak kinerja dalam memberikan kenyamanan termal.

Studi ini meneliti dan membandingkan gedung perkantoran hijau dan konvensional di Taiwan di berbagai aspek selama periode triwulanan penggunaan AC aktif. Di antara variabel lingkungan diamati, tingkat kebisingan, pencahayaan, dan karbon dioksida di kedua jenis bangunan yang sesuai dengan standar internasional atau peraturan Taiwan, tapi tidak senyawa organik yang mudah menguap. Hasil penelitian ini adalah tingkat kepuasan secara keseluruhan (edisi triwulan) penghuni bangunan hijau mempunyai kepuasan lebih 
besar daripada penghuni bangunan konvensional. Sistem sertifikasi green building di Taiwan mampu memfasilitasi kinerja Triwulanan edisi yang tepat dari bangunan. Meskipun untuk evaluasi kinerja selanjutnya, perlu dimasukkan kriteria terkait kenyamanan termal.

Berdasarkan Journal of Green Building: Spring 2012, Vol. 7, No. 2, pp.89104, Oleh Zhonghua Gou, Stephen Siu-Yu Lau, and Zhidong Zhang, dengan judul $A$ Comparison Of Indoor Environmental Satisfaction Between Two Green Buildings And A Conventional Building In China. Hasil dari penelitian ini menunjukkan bahwa bangunan hijau dapat memiliki dampak yang lebih signifikan terhadap kesehatan dan produktivitas penghuni melalui peningkatan kualitas lingkungan dalam ruangan. Namun, setelah hunian menunjukkan bahwa bangunan hijau tidak selalu lebih nyaman dan produktif dibandingkan bangunan non-hijau. Artikel ini menyajikan studi perbandingan antara tiga bangunan di Shenzhen bertujuan untuk menguji kinerja aktual dari bangunan hijau dari sudut pandang penghuni. Dua bangunan hijau menandai kepuasan yang lebih tinggi pada persepsi kesehatan dan produktivitas. Namun, setelah pemeriksaan pada Triwulanan menunjukkan bahwa ada beberapa kelemahan dalam dua bangunan hijau. Kenyamanan dan kepuasan dengan udara dalam ruangan dan suhu pada dua bangunan hijau, baik bila di musim panas namun buruk bila di musim dingin. Salah satu dari dua bangunan hijau memiliki kebisingan lebih dibandingkan bangunan konvensional, sedangkan satu gedung hijau yang lain memiliki pencahayaan yang kurang baik dibandingkan bangunan konvensional. Kesimpulan bahwa perlu dibahas kembali desain green building dan operasionalnya.

Dari International Real Estate
Research Symposium, 2012.inspen.gov.my, oleh Mashitoh Binti Halim, National Property Information Centre (NAPIC), Valuation and Property Services Department, Ministry of Finance Malaysia dengan judul Economic Issues On Green Office Buildings In Malaysia, Proyek penelitian ini menghasilkan isu-isu ekonomi di gedung perkantoran hijau di Malaysia. Ada tiga tujuan utama dalam makalah ini yaitu untuk menyelidiki biaya tambahan konstruksi, manfaat sewa, penghematan biaya operasi dan peningkatan dalam penjualan dan nilai gedung perkantoran hijau di Malaysia. Karena bangunan hijau di Malaysia adalah pasar berkembang, pendekatan terbaik adalah dengan menggunakan pendekatan kualitatif dengan beberapa studi kasus. Penelitian ini menggunakan analisis deskriptif sederhana untuk menganalisis data. Penelitian ini telah menemukan bahwa ada biaya konstruksi tambahan untuk bangunan kantor hijau untuk dikembangkan di Malaysia dan bervariasi sesuai dengan tingkat sertifikasi yaitu sekitar 5\% sampai dengan 15\%. Untuk manfaat sewa, bangunan kantor hijau mengambil tarif sewa yang lebih tinggi sekitar RM 0.50 untuk RM 2.25 per kaki persegi dan pertumbuhan sewa yang lebih tinggi sekitar RM 0.50 untuk RM 1.00 per sq. ft. dibandingkan dengan bangunan konvensional. Gedung kantor hijau juga memberikan keuntungan dalam hal biaya operasional, dapat disimpan uang sekitar RM0.164 per sq.ft dibandingkan dengan bangunan konvensional pada tahun pertama operasi. Sedangkan dalam hal peningkatan harga penjualan dan valuasi belum terbukti belum karena bangunan kantor hijau masih merupakan pasar negara berkembang.

Dari Indoor and Built Environment : SAGE journals, First Published August 29, 2011, oleh Zhonghua Gou, Stephen Siu-Yu Lau, and Zhidong Zhang dengan judul

\begin{tabular}{|l|l|l|l|}
\hline Volume XVIII & Nomor 01 & Maret 2017 & ISSN 1411-1829 \\
\hline
\end{tabular}


Subjective and Objective Evaluation of the Thermal Environment in a Three-Star Green Office Building in China. Sebuah studi pasca-hunian dilakukan untuk menyelidiki lingkungan termal di gedung perkantoran standar tinggi disertifikasi oleh Cina Tiga Bintang Label Green Building. Penelitian ini melibatkan evaluasi subjektif dari kualitas lingkungan dan prestasi kerja dalam ruangan. Sebanyak 182 pekerja kantor merespon survei kuesioner berdasarkan Studi Penggunaan Bangunan (Building Use Studies/BUS) yaitu Survey Penghuni dan Metode Pelaporan. Pengukuran objektif lingkungan thermal gedung (suhu dan kelembaban relatif) dalam kondisi mekanis dan ventilasi alami juga dilakukan. Meskipun mayoritas responden puas dengan lingkungan termal, Namun sekitar 12\% melaporkan ketidak puasan pada musim panas dan $20 \%$ pada musim dingin. Keluhan pada suhu musim panas terutama dari mereka yang bekerja dekat dengan outlet udara dingin dari AC. Sedangkan keluhan pada musim dingin mengungkapkan potensi kelemahan desain bangunan yang berkelanjutan di iklim subtropis yng lembab, di mana ventilasi alami dan pendinginan pasif akan mendominasi dalam desain yang berkelanjutan sementara udara dingin di musim dingin akan cenderung diabaikan.

Pasca Sarjana Universitas Negeri Jakarta, Maret 2017, oleh Ida Umarul Mufidah dengan judul Analisis Komparatif Manajemen Strategis Green Office Antara BPPSDMK dan SEKJEN Di lingkungan KEMENKES R.I. Dalam Memenuhi Standar Pedoman Kantor Hijau Dan Sehat. Persamaan penelitian ini dengan penelitian sebelumnya adalah sama-sama meneliti green office, namun perbedaan penelitian ini dengan penelitian sebelumnya adalah penelitian ini mencari penyebab terjadinya perbedaan kinerja pelaksanaan green office, dari aspek manajemen strategis. Dengan cara membandingkan seluruh tahapan proses manajemen strategis dari mulai environmental scanninng (pemindaian Lingkungan sampai dengan strategic evaluation (Evaluasi strategi).

\section{Hasil Penelitian dan Pembahasan}

Berdasarkan hasil pengumpulan data penelitian, didapatkan hasil yang terdapat pada tabel 2 dan 3 berikut ini:

Tabel 2

Skor Penilaian Aspek Manajemen Strategis dan Implementasi Green Office BPPSDMK dan SEKJEN

\begin{tabular}{|l|c|c|}
\hline \multicolumn{1}{|c|}{ Indikator } & $\begin{array}{c}\text { SKOR } \\
\text { BPPSDMK }\end{array}$ & $\begin{array}{c}\text { SKOR } \\
\text { SEKJEN }\end{array}$ \\
\hline $\begin{array}{l}\text { Pemindaian } \\
\text { lingkungan }\end{array}$ & 4 & $\mathbf{2}$ \\
\hline $\begin{array}{l}\text { Perumusan } \\
\text { Strategi }\end{array}$ & 6 & 3 \\
\hline $\begin{array}{l}\text { Pelaksanaan } \\
\text { Strategi }\end{array}$ & 3 & 3 \\
\hline Evaluasi Strategi & 2 & 1 \\
\hline $\begin{array}{l}\text { Skor Aspek } \\
\text { Manajemen } \\
\text { Strategis }\end{array}$ & $\mathbf{1 5}$ & $\mathbf{9}$ \\
\hline Hemat Energi & 10 & 12 \\
\hline Penyehatan Air & 15 & 15 \\
\hline $\begin{array}{l}\text { Hygiene dan } \\
\text { sanitasi }\end{array}$ & 21 & 17 \\
\hline $\begin{array}{l}\text { Lahan dan } \\
\text { Penghijauan }\end{array}$ & 10 & 7 \\
\hline $\begin{array}{l}\text { Kualitas Udara } \\
\text { Ruang }\end{array}$ & 12 & 12 \\
\hline $\begin{array}{l}\text { Skor Aspek } \\
\text { Implementasi } \\
\text { Green Office }\end{array}$ & $\mathbf{6 8}$ & $\mathbf{6 3}$ \\
\hline Total Skor & $\mathbf{8 3}$ & $\mathbf{7 2}$ \\
\hline
\end{tabular}

Berdasarkan tabel 2 dapat dilihat skor aspek manajemen strategis pada BPPSMK adalah 15 dan Sekjen adalah 9.

\begin{tabular}{|l|l|l|l|}
\hline Volume XVIII & Nomor 01 & Maret 2017 & ISSN 1411-1829 \\
\hline
\end{tabular}


Kemudian skor penilaian pada aspek implementasi green office pada BPPSMK adalah 68 dan Sekjen adalah 63. Adapun skor keseluruhan pada BPPSMK adalah 83 dan Sekjen adalah 72.

\section{Tabel 3}

Skor Perbandingan Kinerja BPPSDMK

SEKJEN Penilaian Aspek Manajemen

Strategis dan Implementasi Green Office BPPSDMK dan SEKJEN

\begin{tabular}{|l|l|}
\hline Indikator & $\begin{array}{l}\text { Perbandingan } \\
\text { Kinerja } \\
\text { BPPSDMK } \\
\text { SEKJEN }\end{array}$ \\
\hline Pemindaian lingkungan & 2,0 \\
\hline Perumusan Strategi & 2,7 \\
\hline Pelaksanaan Strategi & 1,0 \\
\hline Evaluasi Strategi & 2,0 \\
\hline $\begin{array}{l}\text { Skor Manajemen } \\
\text { Strategis }\end{array}$ & 1,7 \\
\hline Hemat Energi & 0,8 \\
\hline Penyehatan Air & 1,0 \\
\hline Hygiene dan sanitasi & 1,2 \\
\hline Lahan dan Penghijauan & 1,4 \\
\hline $\begin{array}{l}\text { Kualitas Udara Dalam } \\
\text { Ruang }\end{array}$ & 1,0 \\
\hline $\begin{array}{l}\text { Skor Aspek } \\
\text { Implementasi GO }\end{array}$ & $\mathbf{1 , 1}$ \\
\hline Total Skor Kinerja & $\mathbf{1 , 2}$ \\
\hline
\end{tabular}

Dari tabel di atas terlihat bahwa perbedaan paling menonjol dari Kinerja penyelenggaraan green office antara BPPSDMK dan SEKJEN yaitu pada aspek implementasi manajemen strategis. Hal ini ditunjukkan dari besarnya nilai perbandingan kinerja dari masing-masing aspek, dimana untuk aspek implementasi manajemen strategis didapatkan sebesar 1,7, sedangkan dari aspek implementasi green office sebesar 1,1.

Nilai perbandingan kinerja tertinggi pada aspek manajemen strategis terdapat pada indikator perumusan strategi yaitu sebesar 2,7, hal ini terjadi karena BPPSDMK sebelum menentukan perumusan strategi terlebih dahulu melakukan pemindaian lingkungan disaat mereka meraih peringkat terakhir dalam penilaian pelaksanaan green office (2013), dimana koordinator green office berupaya memenuhi masukan dari hasil kuesioner pengguna gedung dan tim penilai green office terhadap perbaikan pelaksanaan green office, sehingga ini menjadi dasar bagi koordinator dan tim untuk menentukan tujuan dan strategi yang tepat dalam memenuhi pedoman kantor hijau dan sehat.

Selain tujuan dan strategi yang tepat, hal lain yang menunjang keberhasilan perumusan masalah adalah adanya komitmen pimpinan terhadap pelaksanaan green office dengan dikeluarkannya kebijakan tentang pelaksanaan green office oleh pimpinan BPPSDMK. Komitmen pimpinan merupakan urutan pertama dalam prinsip manajemen green office berdasarkan European Green Office hand book dan Pedoman Kantor Hijau, karena juga seorang pimpinan telah komitmen dengan suatu program, maka dia akan mendukung penuh pelaksanaan program tersebut, baik dari segi kebijakan maupun hal lain yang mendukung terlaksananya program dengan baik.

\section{Kesimpulan}

Kesimpulan penelitian ini adalah : (1) Dari hasil perbandingan manajemen strategis antara BPPSDMK dan SEKJEN didapatkan bahwa implementasi manajemen strategis di BPPSDMK lebih baik dibandingkan SEKJEN, hal ini dapat dilihat dari total nilai implementasi manajemen strategis green office BPPSDMK sebesar 15 dan SEKJEN sebesar 9. Persamaan terletak pada parameter visi dan misi, kebijakan dan anggran, sedangkan perbedaan terletak pada

\begin{tabular}{|l|l|l|l|}
\hline Volume XVIII & Nomor 01 & Maret 2017 & ISSN 1411-1829 \\
\hline
\end{tabular}


pmindaian lingkungan, tujuan, strategi, program dan indikator evaluasi strategi; (2) Implementasi green office di BPPSDMK lebih baik dibandingkan SEKJEN, hal ini dapat dilihat dari total nilai implementasi green office BPPSDMK sebesar 68 dan SEKJEN sebesar 63. Pada penilaian per parameter perolehan total nilai per indikator yang sama dan beda antara BPPSDMK dan SEKJEN. Persamaan nilai antara BPPSDMK dengan SEKJEN terletak pada indikator yaitu penyehatan air dan kualitas udara dalam ruang. Sedangkan Perbedaan nilai terletak pada indikator yaitu hemat energi, hygiene dan sanitasi dan lahan dan penghijauan; (3) Penelitian tentang perbandingan manajemen strategis antara BPPSDMK dan SEKJEN ini dapat menunjukkan semakin baik penerapan majamen strategis pada suatu organisasi, semakin mudah suatu organisasi mencapai tujuan organisasi; dan (3) Perumusan strategi BPPSDMK untuk melakukan perbaikan disaat meraih peringkat terakhir tahun 2013 dan menjadi yang terbaik pada tahun 2016 dalam penilaian pelaksanaan green office merupakan indikator manajemen strategis diperlukan pada aktivitas organisasi.

\section{Daftar Pustaka}

Dirjen PP dan PL KEMENKES, Pedoman Kantor Hijjau dan Sehat, Kementerian Kesehatan Republik Indonesia. 2015

European Green Office, European Green Office Handbook.

Http://www.eugreenoffice.eu/userfile s/ego_handbook_eng.pdf.Diakses tanggal 17 oktober 2016

Gou, Zhonghua et.al, "A Comparison Of Indoor Environmental Satisfaction Between Two Green Buildings And A Conventional Building In China."
China: Journal of Green Building: Spring 2012, Vol. 7, No. 2.

Gou, Zhonghua et.al, "Subjective and Objective Evaluation of the Thermal Environment in a Three-Star Green Office Building in China." China : Indoor and Built Environment : SAGE journals, First Published August 29, 2011.

Halim, Mashitoh Binti, "Economic Issues on Green Office Buildings in Malaysia."Malaysia : International Real Estate Research Symposium, 2012 .- inspen.gov.my

Liang, Han-Hsi et.al, "Satisfaction of occupants toward indoor environment quality of certified green office buildings in Taiwan."Taiwan : Building and Environment Vol.72, 2014.

Pearce, John A. \& Richard B, Strategic Management Formulation, implementation, and control. 13th Edition.Boston : McGraw-Hill School Education Group, 2013.

Peia, Zufeng et.al,"Comparative study on the indoor environment quality of green office buildings in China with a long-term field measurement and investigation." China: Building dan Environment: Elsevier Volume 84, January 2015.

Walk, Kerry, "for the writing center at Harvard University and Comparative Analysis." General strategies of Comparative method, copyright 1998.

Website enviro, http://www.enviro/greenoffice (diakses tanggal 16 oktober 2016)

Websitefokal,http://www.fokal.info/fokal/ 2013/05/green-officekantor-masa depan(diakses tanggal 16 oktober 2016)

Website GBCI, The Definition in Creating

\begin{tabular}{|l|l|l|l|}
\hline Volume XVIII & Nomor 01 & Maret 2017 & ISSN 1411-1829 \\
\hline
\end{tabular}


Green Offices. http://www.gbcindonesia.org/attach ments/article/99/ECO\%20OFFICE2. pdf. Diakses tanggal 17 oktober 2016 Website Green Harvard, http://www.green.harvard.edu/progra $\mathrm{ms} /$ green-offices/green-office- resources. Diakses tanggal 17 oktober 2016. Website WWF Finlandia, http://www.wwf.fi/green_office.WW F Finland. 2011 (diakses tanggal 17 oktober 2016).

\begin{tabular}{|l|l|l|l|}
\hline Volume XVIII & Nomor 01 & Maret 2017 & ISSN 1411-1829 \\
\hline
\end{tabular}

